\title{
Deformation monitoring using laser scanned point clouds and BIM
}

\author{
Vladimir Badenko ${ }^{1}$, Dmitry Volgin ${ }^{1}$, and Sergey Lytkin ${ }^{1, *}$ \\ ${ }^{1}$ Peter the Great St. Petersburg Polytechnic University, Polytechnicheskaya 29, St. Petersburg, \\ 195251, Russian Federation
}

\begin{abstract}
Laser scanning is an essential method for monitoring of the operation of buildings or structures. It involves creating as-is BIM from point clouds obtained from laser scanning. In this article we present our workflow for the generation of information model from 3D point clouds of concrete tetrapod blocks on navigable structure $\mathrm{C}-1$. Point cloud processing method for making informational model for long term monitoring is described. As a result of the research BIM model with each tetrapod was created for deformational monitoring in the comparison with next year model. Finally, we identify and discuss technology gaps that need to be addressed in future research.
\end{abstract}

\section{Introduction}

The creation of an as-built BIM involves measuring the geometry and appearance of an existing facility and transforming those measurements into a high-level, semantically rich representation [1]. One of the major challenges while implementing BIM technology is to monitor the operation of the building or structure after its construction. In this regard the method of laser scanning of the structure is used. Essentially, the laser scanning technology involves determination of the spatial coordinates of the object's surface. The growing interest in recent years in LIDAR by the scientific community, software developers, and geomatics professionals, has led these systems to be used more and more widely, in different fields of engineering and architecture. Laser scanning is a fundamental method of monitoring buildings and structures after their construction. It consists in creating an information model of the structure based on a three-dimensional point clouds obtained during scanning. However, data processing methods may vary depending on the object being scanned and the desired result [2-6]. Monitoring structural deformation is one of the major concerns when dealing with structures such as bridges, tunnels, dams and tall buildings [7].

There are some examples of applying of TSL techniques in a field of deformation monitoring. Zogg and Ingensand uses a TSL techniques to detect absolute deformations of the bridge girder [8]. Lõhmus et al. also used terrestrial laser scanning for the monitoring [9]. Thomson and Boehm investigates the opportunity of automatic geometry generation from point clouds for BIM [10]. Wei et al. demonstrates the results of monitoring by

\footnotetext{
*Corresponding author: 1ytkin.sa@edu.spbstu.ru
} 
combining terrestrial laser scanning, close range photogrammetry and 3D reconstruction technologies [11]. Holst and Kuhlmann mentions several methodical challenges that represent the model based fields of action at laser scanner based deformation analyses [12]. Lindenbergh and Pietrzyk give us a review of recent methods aiming at detecting changes from laser scan data [13]. Yang et al. are carried out an arch structures under monotonic loads measurement based on terrestrial laser scanning technology [14]. Soni et al. describes the application of TLS to the monitoring of a set of masonry arches during a major station refurbishment [15]. Qiu and $\mathrm{Wu}$ applied the terrestrial laser scanning technology to monitor the deformation of subway tunnel structure [16]. Jaafar et al. showed new approach for monitoring historic and heritage buildings based on terrestrial laser scanning [17].

Barazzetti et al. describes the way of creating a historic building model from point clouds and convert it into a finite element model for structural simulation [18]. Xiong et al. survey several methods of automated as-built BIM creation and discuss their potential application [19]. Brilakis et al. presents a novel framework that holds promise to automate almost entirely the generation of as-built parametric BIMs of constructed facilities, ranging from residential housing to industrial structures [20]. Barazzetti et al. presents a novel semiautomated method for the generation of 3D parametric as-built models from point clouds $[21,22]$. Guarnieri et al. merge data derived from close-range photogrammetry and from terrestrial laser scanning in a unique product in such a way that the final model could be seamlessly explored [23]. In turn, BIM models are needed to improve the management of construction objects [24-27].

On the base of literature review it is possible to claim that searching for methods of creating information models using the technology of laser scanning for performing deformation long-term monitoring for buildings and structures is actual research task. But nowadays optimal approach for laser scanning data processing does not exist.

The objective of this research is to demonstrate algorithms of processing point cloud data and creating information model for long-term deformation monitoring for concrete tetrapod blocks on navigable structure $\mathrm{C}-1$.

\section{Methods}

This article is presented on the basis of laser scanning data of navigation structure C-1 of the complex of structures protecting St. Petersburg from floods, which is located on the border of the Neva Bay and the Gulf of Finland of the Baltic sea, in the Southern gate (between Kotlin island and p. Bronka). The object of research consists of four breakwaters. The article describes the processing algorithm on the example of one of them.

Temporary paper stamps were fixed on the walls of concrete parapets from the outside and from the inside as points of shooting justification. Coordination of the marks was carried out by means of an electronic total station Leica TS 15AR1000 1 "by building a linear-angular network. The phase terrestrial laser scanner Faro Focus 3D was used to perform the works (Fig. 1).

This system allows to effectively scan at a distance of 50-70 meters with an accuracy of determining distances up to $2 \mathrm{~mm}$. To obtain a complete three-dimensional point model of one mole, an average scan was performed from 30 stations located on the parapet and at the base of the slope of the mole. 


\section{EECE-2018}

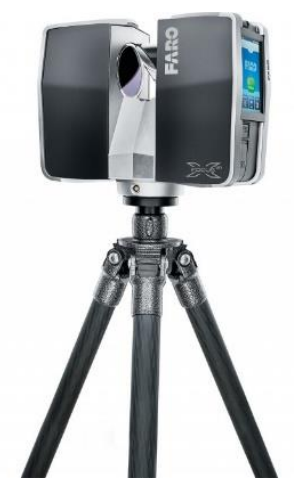

Fig. 1. Terrestrial laser scanner Faro Focus 3D

The measurements at each station were made in the coordinate system associated with the scanner. To combine the results of scanning from various scanner stations to the common coordinate system, special scanner marks were used. Coordinates of scanner marks in the coordinate system of the scanner are determined on the basis of the analysis of a cloud of points, and the coordinates of marks in the working coordinate system were determined by polar notches using an electronic total station.

In this article we propose the following algorithm of data processing with the use of different software (fig. 2):

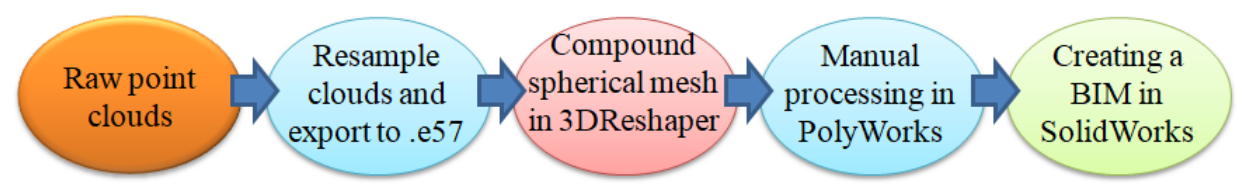

Fig. 2. Algorithm for obtaining information model

Point clouds obtained during the survey were imported into the Autodesk ReCap software, where they were oriented along overlapping parts of point clouds. RCP project consists of $\sim 300$ million points. The initial data is shown in Fig. 3.

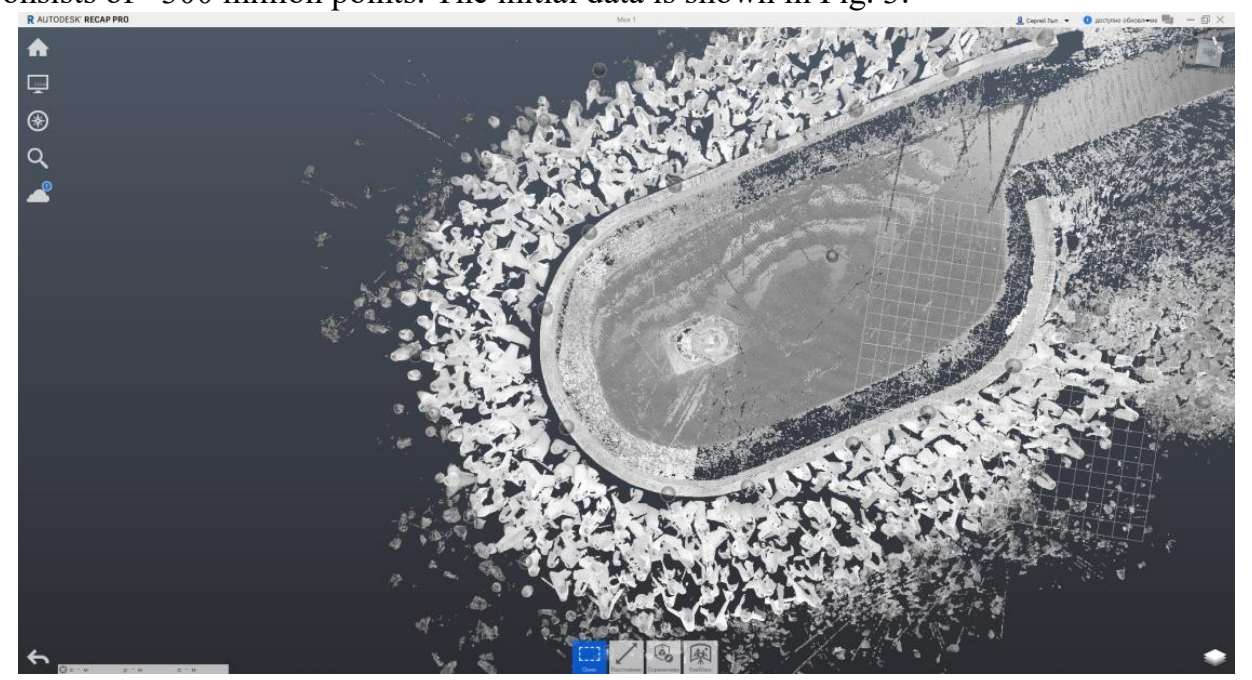

Fig. 3. Raw point clouds 
To optimize the number of points on the scans and improve their deciphering properties, the materials were filtered. Resampling points can reduce the number of points in areas of too high density (near the scanning station), keeping the density of points in the more distant parts of the object. The raw point clouds were simplified by $80 \%$, it significantly reduced the density of the clouds and made further processing possible. After the preprocessing of initial data, the cloud was exported in a E57 format. In this format, scanning positions and the coordinates of the points with parameters of intensity and RGB are saved. The resulting file in 3DReshaper is transformed into a Spherical Mesh, after which the exported polygon surface is exported to PolyWorks software. In order to fix the vertex of each tetrapod in space, it is necessary to describe the polygonal model using truncated cones. Then the primitives describing the spatial arrangement of the tetrapods are extracted in the SolidWorks software in IGS format, where according to GOST-20425-75 (Tetrapods for bank protection and fencing structures) a typical tetrapod is modeled and its orientation in space relative to the truncated cones (fig. 4). After that, each tetrapode is assigned its own number to automatically find the values of the displacements relative to the next scan cycle.

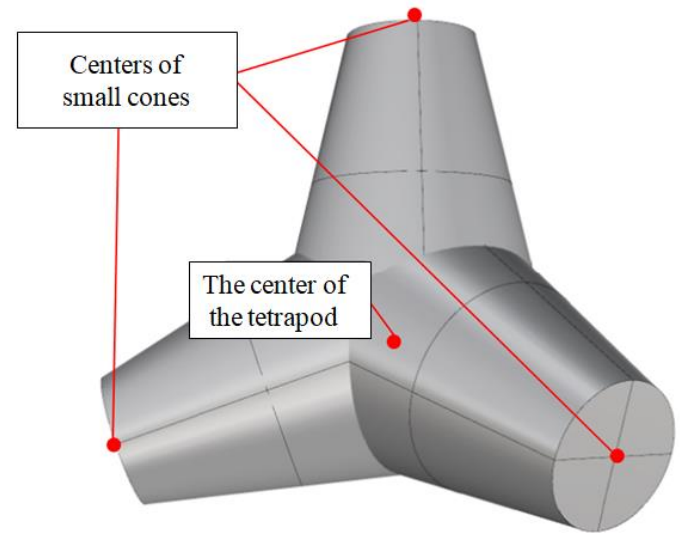

Fig.4. Characteristic points of an individual tetrapod.

\section{Results and Discussion}

The result of cloud processing in 3DReshaper software is shown in Fig. 5.

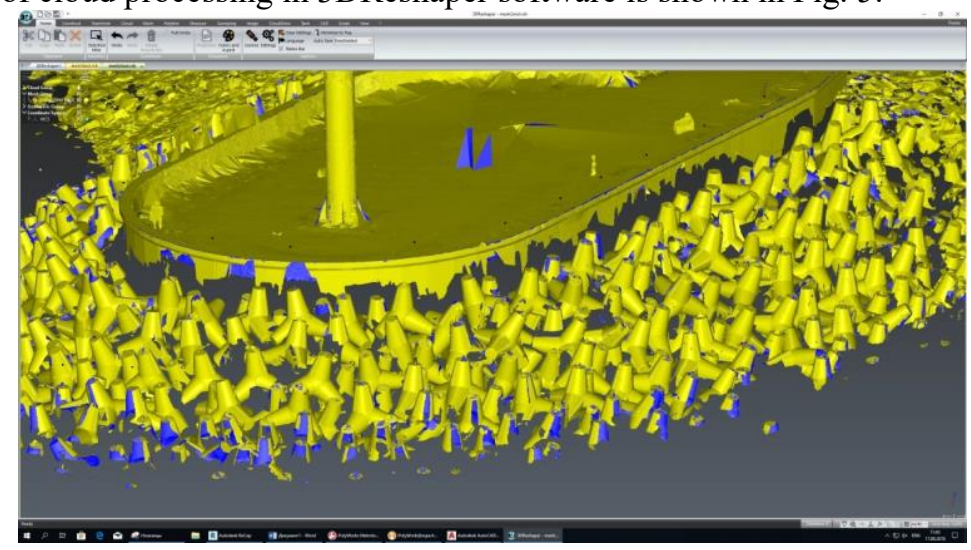

Fig. 5. Compound spherical mesh. 
The process of extracting the primitive is shown in Fig. 6 .

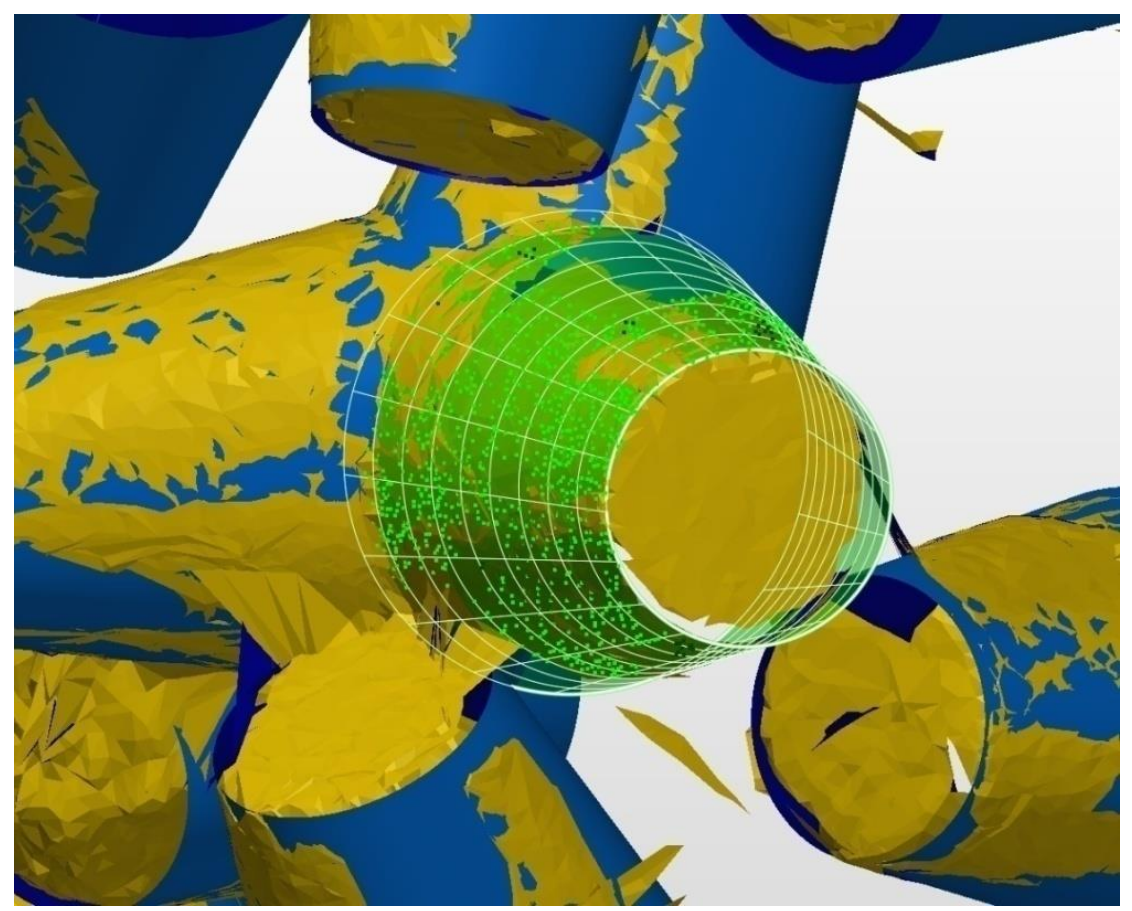

Fig. 6. Extracting the primitive in PolyWorks software

Light green dots indicate areas of intersection of the extracted primitive with a polygonal model, dark green areas are areas of a polygonal model that are a few millimeters inward from the surface of the primitive and do not intersect with the primitive. Thus, the greener points, the more accurately the primitive is inscribed.

The extracted primitives are shown in Fig. 7.

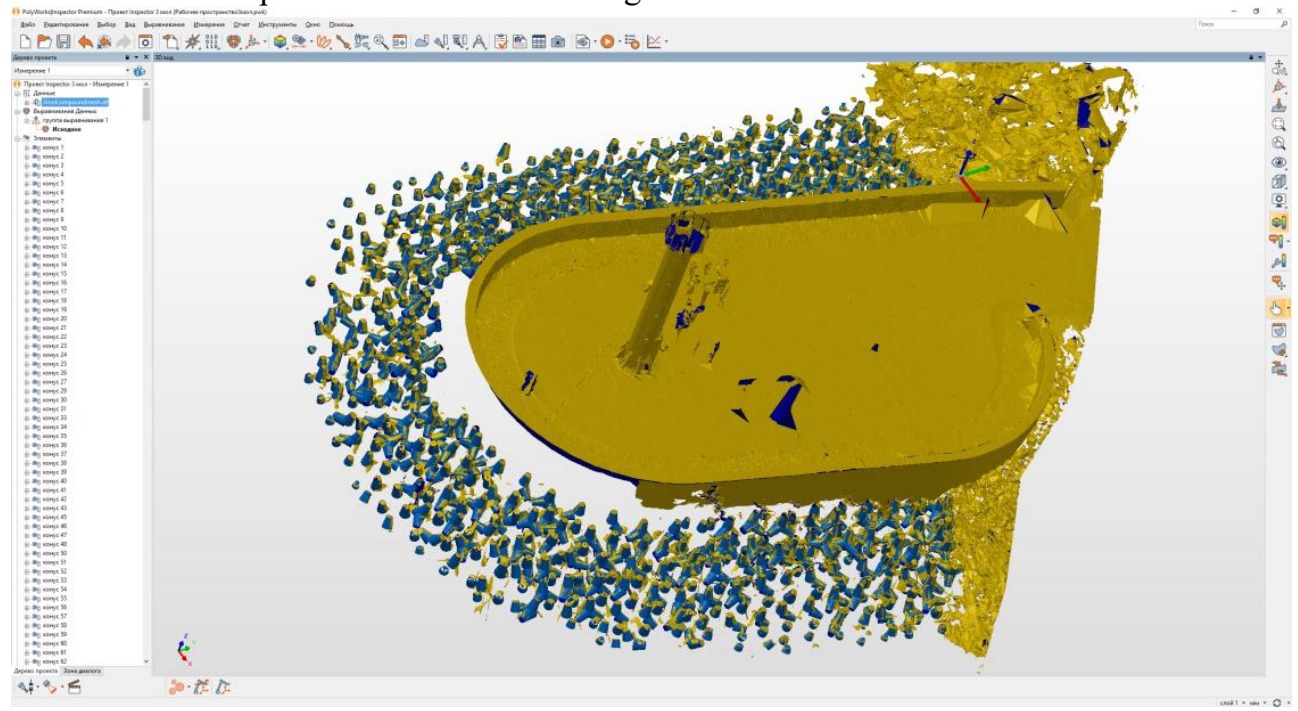

Fig. 7. Extracted primitives 
The final BIM is shown in Fig. 8.

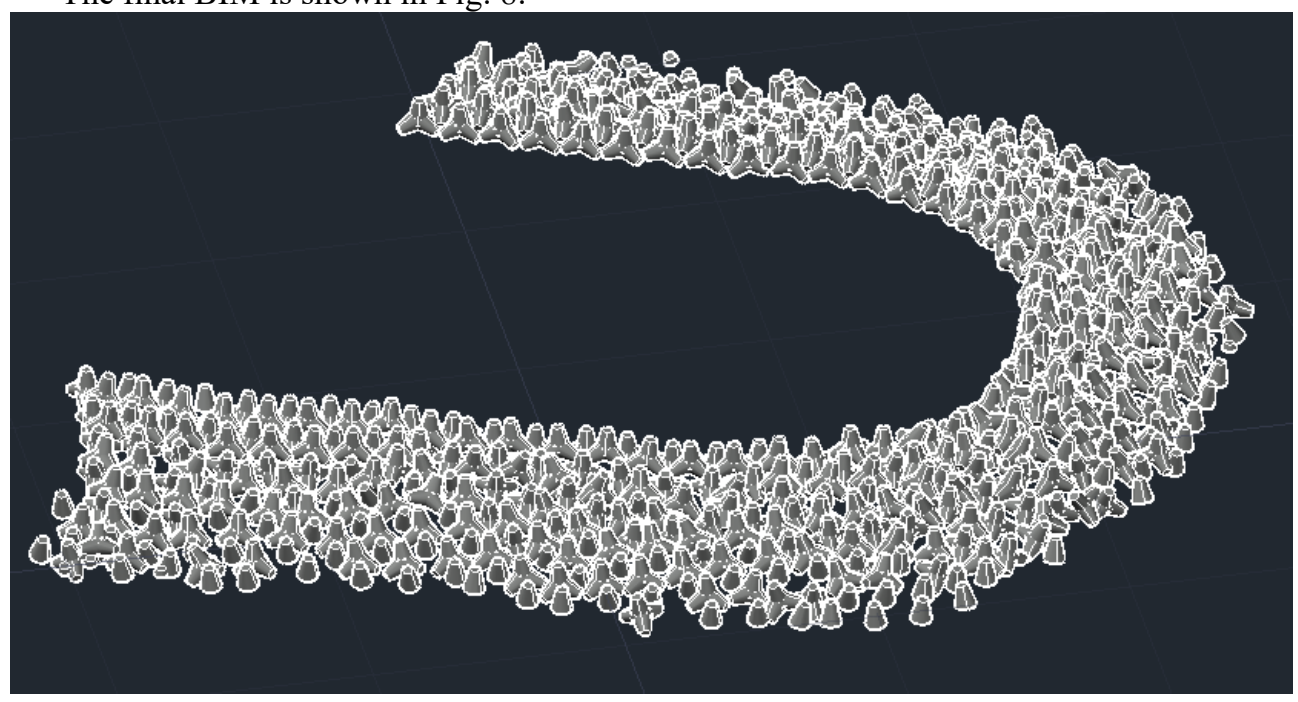

Fig. 8. Final BIM of single tetrapods

During the processing of the "cleared" cloud, a lack of our simplification method was revealed: ReCap during the "Clear" operation defines a part of the cloud as noise, which leads to a decrease in the informative value of the point cloud (Fig. 9).

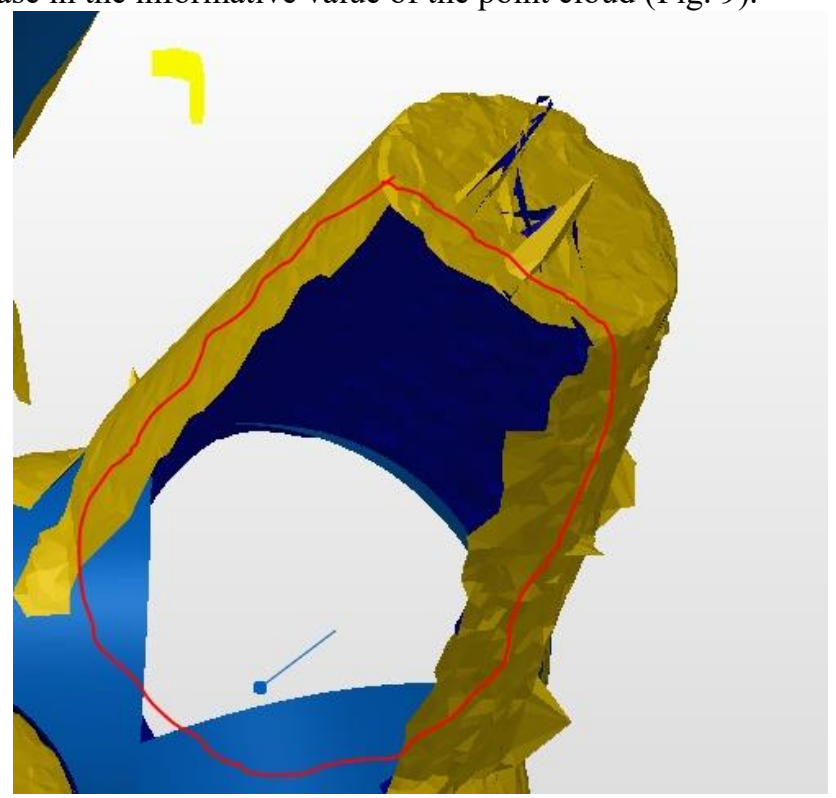

Fig. 9. Demonstration of the consequences of cloud cleaning in ReCap software

In fact, this shortcoming did not play a significant role. One way to solve this problem is to perform preliminary cloud segmentation in density in the CloudCompare software and subsequent cleaning of high-density areas. The described method is quite laborious because of the large amount of manual work. Thus, the search for an alternative approach to cloud pre-processing, as well as automation of the process of building the information model, are 
promising directions for further research. The obtained information model will be used for comparative analysis on the next cycle of monitoring.

\section{Conclusions}

1) To perform this work, the laser scanner Faro Focus 3D was used;

2) An algorithm for constructing an information model of tetrapods on the heads of wave protection malls of the navigational structure $\mathrm{C}-1$ of a complex of flood defensive structures in St. Petersburg for geodetic monitoring using modern technologies is described;

3) Pre-processing of the cloud was made;

4) Compound spherical mesh is obtained;

5) An information model of individual tetrapods based on the point cloud is obtained;

6) Technology gaps were identified and discussed the ways to solve them.

\section{Acknowledgements}

The research was supported by Ministry of Science and High Education of Russia within the framework of the Federal Program (project ID RFMEFI58417X0025).

\section{References}

1. P. Tang, D. Huber, B. Akinci, R. Lipman, A. Lytle, Automat. Constr., 19, 829-843 (2010)

2. E. Fateeva, V. Badenko, A. Fedotov, I. Kochetkov, MATEC Web of Conferences, 170 (2018)

3. V. Badenko, A. Fedotov, and D. Zotov, SHS Web of Conferences, 44 (2018)

4. V. Badenko, D. Zotov, A. Fedotov, E3S Web of Conferences, 33 (2018)

5. V.N. Demkin, V.A. Stepanov, M.V. Shadrin, St. Petersburg State Polytechnical University Journal. Physics and Mathematics, 3(177), 136-143 (2013)

6. K.D. Babkin, E.V. Zemliakov, G.A. Turichin, A.V. Kuznezov, St. Petersburg State Polytechnic University Journal of Engineering Science and Technology, 3(226), 142149 (2015)

7. J.Y. Han, J. Guo, Y.S. Jiang, Tunn. Undergr. Sp. Tech., 33, 186-192(2013)

8. H.M. Zogg, H. Ingensand, ISPRS Archives, 37, 555-562 (2008)

9. H. Lõhmus, A. Ellmann, S. Märdla, S. Idnurm, Surv. Rev., 50, 270-284 (2018)

10. C. Thomson, J. Boehm, Remote Sens (Basel), 7, 11753-11775 (2015)

11. Z. Wei, G. Huadong, L. Qi, H. Tianhua, IOP Conf. Ser.: Earth Environ. Sci., 17 (2014)

12. C. Holst, H. Kuhlmann, JAG., 10, 17-25 (2016)

13. R. Lindenbergh, P. Pietrzyk, AG., 7, 65-74 (2015)

14. H. Yang, M. Omidalizarandi, X. Xu, I. Neumann, Compos. Struct., 169, 173-179 (2017)

15. A. Soni, S. Robson, B. Gleeson, AG.,7, 123-138 (2015)

16. D.W. Qiu, J.G. Wu, ISPRS Archives, 3, 491-494 (2008)

17. H.A. Jaafar, X. Meng, A. Sowter, P. Bryan, Struct. Control. Hlth., 24 (2017)

18. L. Barazzetti, F. Banfi, R. Brumana, G. Gusmeroli, M. Previtali, G. Schiantarelli, Simul. Model. Pract. Th., 57, 71-87 (2015)

19. X. Xiong, A. Adan, B. Akinci, D. Huber, Automat. Constr., 31, 325-337 (2013)

20. I. Brilakis, M. Lourakis, R. Sacks, S. Savarese, S. Christodoulou, J. Teizer, A. Makhmalbaf, Adv. Eng. Inform., 24, 456-465 (2010) 
21. L. Barazzetti, F. Banfi, R. Brumana, F. Roncoroni, M. Previtali, ISPRS Archives, 51-56 (2016)

22. L. Barazzetti, Adv. Eng. Inform., 30, 298-311 (2016)

23. A. Guarnieri, N. Milan, A. Vettore, Int. J. Archit. Herit., 7, 54-67 (2013).

24. A. Borodinecs, J. Zemitis, J. Sorokins, D.V. Baranova, D.O. Sovetnikov, Mag. Civ. Eng., 8, 58-64 (2016)

25. V.V. Sharmanov, T.L. Simankina, A.E. Mamaev, Mag. Civ. Eng., 69(1), 77-88 (2017)

26. N.V. Gusakova, K.E. Filyushina, A.M. Gusakov, N.N. Minaev, Mag. Civ. Eng., 75(7), 84-93 (2017)

27. T.V. Bobrova, P.M. Panchenko, Mag. Civ. Eng., 76, 84-97 (2017) 